\title{
O Programa UFBA em Campo - ACC: sua contribuição na formação do estudante
}

\author{
RESUMO: Este artigo originou-se de minha dissertação que objetivou avaliar \\ o Programa UFBA em Campo - ACC através da perspectiva dos egressos dos \\ cursos de graduação da UFBA. Para orientar a pesquisa, foram definidos seis \\ objetivos: a) Entender que concepção de extensão e de intervenção social a \\ UFBA possui; b) Verificar se há articulação entre as atividades de ACC e as de \\ ensino e pesquisa e como isso se processa; c) Examinar a existência de articu- \\ lação das temáticas de ACC com os problemas sociais; d) Descrever as políticas \\ existentes na UFBA para o desenvolvimento da ACC e se existem incentivos \\ institucionais e ou de outras fontes; e) Entender como é a participação dos \\ estudantes nas ACC; f) Examinar a contribuição da ACC na formação estu- \\ dantil. A pesquisa realizada através da pesquisa bibliográfica, da metodologia \\ do survey e da pesquisa documental verificou que a UFBA utiliza o mesmo \\ conceito elaborado pelo Plano Nacional de Extensão Universitária, com a ACC \\ em sua essência articulando as funções essenciais da Universidade. A pesqui- \\ sa apontou que a Universidade possui políticas institucionais para o desenvol- \\ vimento da ACC e que o programa desempenha um papel importante no \\ trajeto curricular do estudante, contribuindo para a formação ética, profissio- \\ nal, cidadã e humanitária. \\ PALAVRAS-CHAVE: Programa de extensão. Atividade Curricular em Comu- \\ nidade (ACC). Universidade Federal da Bahia.

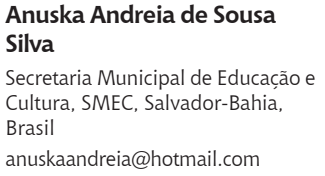

\section{Introdução e Objetivos}

Não há um conceito único sobre Universidade e nem suas funções foram as mesmas de acordo com o tempo e o espaço. A concepção de Universidade mais difundida hoje é que ela é uma instituição social responsável por geração e divulgação do saber. Para cumprir tal papel, a Universidade possui funções. Essas funções são variadas de acordo com os estudiosos, o tempo e o espaço, mas há algumas consideradas as principais: o ensino, a pesquisa e a extensão.

É importante mencionar que esse é um entendimento recente acerca de quais são as mais importantes funções universitárias, pois quando a Universidade surgiu no Brasil (influenciada por diversos modelos) havia apenas o ensino como meio de formar os profissionais de acordo com as necessidades da elite dirigente da sociedade aristocrática da época.

Com as demandas da sociedade industrial, a Universidade foi sendo reformada de modo a acompanhar as mudanças e foi então que a pesquisa foi inserida como mais uma função universitária. 
Mesmo com duas funções principais - o ensino e a pesquisa - a Universidade, segundo estudiosos, ainda não mantinha uma relação satisfatória com o meio social. Foi para implementar a relação entre Universidade e sociedade que a extensão foi incorporada às duas outras funções, principalmente influenciada pelo Movimento de Córdoba/Argentina, em 1918. (MAZZILLI, 1996)

Segundo Botomé (1996, p. 58), a extensão veio tentar realizar o compromisso social da Universidade que o ensino e a pesquisa não estavam desenvolvendo. Logo, a extensão é considerada por ele uma atividade temporária, ou seja, quando o ensino e a pesquisa realizarem seus papéis plenamente, a extensão vai perder o sentido de existir.

Os estudos acerca da atividade extensionista apontam que a primeira experiência na Europa ocorreu na Universidade de Oxford, na Inglaterra, em 1845, através de programas de Educação de Adultos e em seguida por meio de cursos que atendiam aos anseios das demandas sociais. Já nos Estados Unidos, a origem da extensão universitária foi no século XIX em Universidades Populares e ao modelo norte-americano de extensão rural com caráter de prestação de serviços, cujo objetivo era o desenvolvimento econômico via investimentos em atividades agrícolas devido a crescente competição capitalista.

No Brasil, "Na Universidade Livre de São Paulo foi definida a primeira formulação extensionista do país: os cursos de extensão. Estes, ainda hoje, representam a prática extensionista mais conhecida e difundida nacionalmente". (GURGEL, 1986 apud MESQUITA, 2001, p. 35) Havia a prática de oferecimento de cursos e de conferências semanais por algumas universidades denominadas de populares, tais como a do Amazonas em 1909, a de São Paulo (que ampliou tal prática a partir de 1911) e a do Paraná. (MESQUITA, 2001)

É importante salientar que a atividade extensionista no Brasil é entendida em duas concepções, a partir das formas em que são exercidas. Na primeira concepção, a extensão é entendida como via de mão única, através de prestação de serviços em forma de cursos, onde a Universidade apenas "leva" o conhecimento à comunidade. Na segunda, a extensão universitária é entendida como via de mão dupla, através de troca de benefícios entre a Universidade e a comunidade.

84 R. Faced, Salvador, n.13, p.83-102, jan./jun. 2008 
A prática da extensão universitária é entendida como via de mão única quando ela apenas vai à comunidade, através de elaboração da prestação de serviços em forma de cursos que possam expandir o conhecimento produzido academicamente, onde por esta prática, a universidade se apresenta como detentora do saber, do conhecimento, salvadora, colocando e levando o seu conhecimento às camadas populares, ignorando todo e qualquer conhecimento existente por parte destas. (SILVA, 2001)

Já na segunda concepção, "[...] a extensão é entendida como via de mão dupla, onde ela contribui para as camadas populares e, estas por sua vez, dão retorno através da exposição e amostra de suas realidades". (SILVA, 2001)

Além de tais concepções, há outros conceitos que se têm acerca da extensão universitária. Diversos autores defendem o conceito de extensão como atividade de integração do ensino e pesquisa e da relação da universidade-sociedade.

Percebe-se que essa compreensão acerca da atividade extensionista, entendendo como instrumento articulador entre as funções universitárias, vem se configurando na prática no âmbito da Universidade Federal da Bahia, especialmente desde 1997, quando foi criado o Programa UFBA em Campo (projeto universitário de extensão cultural que envolvia alunos, professores e comunidades), atualmente denominado Programa UFBA em Campo - Atividade Curricular em Comunidade (ACC).

O Programa UFBA em Campo - ACC utiliza o mesmo conceito de extensão defendido pelo Plano Nacional de Extensão Universitária: "[...] a extensão universitária é o processo educativo, cultural e científico que articula o ensino e a pesquisa de forma indissociável e viabiliza a relação transformadora entre Universidade e Sociedade" (FÓRUM NACIONAL DE PRÓ-REITORES DE EXRENSÃO DAS UNIVERSIDADES PÚBLICAS BRASILEIRAS BRASIL, [2001?]). A Reforma Universitária de 1968 já definia a indissociabilidade das funções universitárias básicas: ensino, pesquisa e extensão.

Na UFBA, como já foi mencionado, a extensão vinha ocorrendo através da clássica categorização das atividades em cursos, eventos, serviços, programas e projetos. Porém, destacamos a criação do Programa UFBA em Campo em 1997, pela Pró-Reitoria de Extensão, que resultou como produto a ACC, que foi inserida no currículo dos cursos de graduação da mesma Universidade, em 2001. 
Assim, o objeto de investigação da pesquisa foi o estudo é a ACC - atividade extensionista oferecida pela UFBA a todos os estudantes de graduação como componente curricular - avaliada a partir da perspectiva dos seus egressos (monitores e participantes), bem como os demais participantes desta atividade, em relação a um conjunto de questões que serão mais adiante explicitadas.

Desse modo, a proposta da pesquisa foi avaliar a ACC na perspectiva da avaliação institucional. Foram consideradas as questões definidas pela Comissão Nacional de Avaliação da Educação Superior (CONAES) e o Instituto Nacional de Estudos Pedagógicos (INEP), a autoavaliação das IES no Sistema Nacional de Avaliação da Educação Superior (SINAES), no que diz respeito à extensão e outras propostas de interesse específico da investigação.

O roteiro de autoavaliação definido pela CONAES e INEP apresenta dois núcleos de enfoque. O primeiro é denominado básico e comum. O segundo de temas optativos. Aqui foram consideradas as orientações de ambos os núcleos.

No núcleo básico e comum têm-se as seguintes questões: qual a concepção de extensão e de intervenção social afirmada no PDI? Há articulação das atividades de extensão com o ensino e a pesquisa e com as necessidades e demandas do entorno social? Como é a participação dos estudantes nas ações de extensão e intervenção social e o respectivo impacto em sua formação?

Já no núcleo de temas optativos têm-se: Há um órgão institucional responsável pela coordenação das atividades e política de extensão? Qual sua dinâmica de funcionamento? Há preocupação da IES em desenvolver atividades de extensão que atendam à comunidade regional em termos sociais, culturais, da saúde e outros? Como se manifesta? Há sistemáticas de avaliação das atividades de extensão desenvolvidas pela IES? Quais? Qual o impacto das atividades de extensão na comunidade e na formação dos estudantes? As atividades de extensão desenvolvidas estão integradas com as de ensino e pesquisa? São coerentes com a missão da IES? Quais são as formas de integração? Quais as políticas existentes na instituição para o desenvolvimento das atividades de extensão? Existem incentivos institucionais ou de outras fontes? Quais são eles?

Como o enfoque da investigação foi apenas sobre uma ação extensionista da UFBA - a ACC - foram escolhidas algumas questões das acima citadas. Logo, o tema foi problematizado nas se- 
guintes perguntas: 1) Qual a concepção de extensão e de intervenção social da IES (UFBA)? As atividades de extensão (ACC) desenvolvidas estão integradas com as de ensino e pesquisa? São coerentes com a missão da IES (UFBA)? Quais são as formas de integração? Há preocupação da IES (UFBA) em desenvolver atividades de extensão (ACC) que atendam à comunidade regional em termos sociais, culturais, da saúde e outros? Como se manifesta? Quais as políticas existentes na instituição para o desenvolvimento das atividades de extensão (ACC)? Existem incentivos institucionais ou de outras fontes? Quais são eles? Como é a participação dos estudantes nas ações de extensão (ACC) e intervenção social e o respectivo impacto em sua formação? Há sistemáticas de avaliação das atividades de extensão (ACC) desenvolvidas pela IES (UFBA)?

É importante destacar que até a realização da pesquisa a ACC ainda não tinha sido objeto de estudo sistematizado. Assim, a realização da pesquisa poderá contribuir para o planejamento e aprimoramento das atividades institucionais, dentre elas a ACC, bem como prestar contas à sociedade das atividades desenvolvidas juntamente com os resultados obtidos.

A avaliação institucional tornou-se um dos mecanismos essenciais ao planejamento, tomada de decisão e aprimoramento das atividades das Instituições de Ensino Superior (IES), tendo como consequência uma melhoria na administração das Universidades.

Através da avaliação, a Universidade se informa da eficiência ou qualidade dos seus serviços educacionais e profissionais oferecidos à sociedade. Com isso, a Universidade terá subsídios seguros para (re)dimensionar diretrizes, rever objetivos, (re)atualizar programas, elaborando alternativas que favoreçam a qualificação profissional, enfatizando também o desenvolvimento do indivíduo enquanto ser humano e cidadão.

Assim, ter a ACC como objeto de investigação a partir da perspectiva dos atores que dela participam possibilitará à UFBA o autoconhecimento e a tomada de decisão com a finalidade de aperfeiçoar seu funcionamento, além disso, os resultados da pesquisa poderão subsidiar a autoavaliação da IES, tal como foi exigida pelo SINAES.

Sabe-se que desde a inserção da ACC como componente curricular dos cursos de graduação da UFBA em 2001, e até mes- 
mo antes com o Programa UFBA em Campo, que essa atividade extensionista vem sendo mencionada no âmbito institucional, com seus resultados apresentados nos relatórios anuais e ou de gestão da UFBA, socializados nos Fóruns de Pró-Reitores de Extensão das Universidades Públicas Brasileiras e SESu/MEC, e publicados em livros e fitas de vídeo.

Tais reflexões e ações são de suma importância e precisam permanecer, mas é necessário que a avaliação desta atividade, como de qualquer outra desenvolvida pela Universidade, seja realizada em sua totalidade desde sua origem, em 1997, bem como no seu percurso histórico como prática rotineira das atividades da UFBA.

Assim, o geral da investigação foi: Avaliar o Programa UFBA em Campo - ACC através da perspectiva dos egressos estudantes dos cursos de graduação da UFBA. Quanto aos específicos, têm-se: Levantar a concepção de extensão e de intervenção social da IES (UFBA); Investigar a articulação entre as atividades de ACC e as de ensino e pesquisa; Investigar a articulação das temáticas de ACC com problemas sociais; Descrever as políticas existentes na instituição para o desenvolvimento das atividades de extensão (ACC) e se existe incentivos institucionais e/ou de outras fontes; Analisar a participação dos estudantes nas ações de extensão (ACC) e intervenção social; Analisar a contribuição da ACC na formação do estudante. No que tange à metodologia, adotamos a pesquisa bibliográfica, a metodologia do survey e a pesquisa documental.

\section{Metodologia}

As estratégias de pesquisa utilizadas para desenvolver o estudo foram a pesquisa bibliográfica, a metodologia do survey e a pesquisa documental.

Como o problema central da investigação foi verificar qual a contribuição do Programa UFBA em Campo - ACC, para a formação do estudante de graduação da UFBA, o primeiro passo que adotamos na elaboração da pesquisa foi o levantamento documental sobre os antecedentes e o processo de criação da ACC, bem como todo o percurso da ACC desde o programa anterior a esse (Programa UFBA em Campo), perpassando pelo caráter experimental da atividade (2001.1 - 2002.2) até como programa permanente na atual conjuntura da universidade. 
Continuamos com a pesquisa documental juntamente com a pesquisa bibliográfica com o intuito de responder outra questão da pesquisa que é entender qual a concepção de extensão e de intervenção social da UFBA. Uma entrevista com o Professor Álamo Pimentel (Pró-reitor de Extensão da UFBA / 2004 - 2006), realizada no final da pesquisa, também auxiliou na elucidação da questão.

Depois dessas primeiras análises documentais e revisão de literatura, partimos para a realização de entrevistas com pró-reitores, ex-pró-reitores, ex-coordenadora do programa e aplicação de questionários com os estudantes egressos.

Nas entrevistas, colhemos impressões acerca da temática da Professora Bela Serpa (Coordenadora do Programa ACC/1999 2005), do Professor Álamo Pimentel (Pró-reitor de Extensão da UFBA / 2004 - 2006), do Professor Maerbal Bittencourt Marinho (Pró-reitor de Graduação da UFBA/ 0000 - 0000) e do Professor Paulo Lima (Pró-reitor de Extensão da UFBA / 1999 - 2002). Houve a intenção de entrevistar também o Pró-reitor de Pesquisa e Pós-Graduação, com o intuito de verificar questões de articulação das três pró-reitorias da UFBA mais ligadas ao currículo do curso de graduação (Pró-Reitoria de Ensino e Graduação, Pró-reitoria de Extensão Universitária e Pró-Reitoria de Pesquisa e PósGraduação), mas não conseguimos realizar devido à agenda lotada do atual pró-reitor de Pesquisa e Pós-Graduação. As entrevistas foram realizadas entre os meses de julho e novembro de 2006, de acordo com a disponibilidade dos entrevistados.

Inicialmente, sorteamos $20 \%$ da população total de estudantes que participaram de ACC, o que deu um total de 70 ACC, pois o número de ACC até o ano de 2006 oferecido foi de 367.

A entrega ou o envio dos questionários para os egressos da ACC ocorreu durante os meses de agosto e dezembro de 2006. O primeiro passo foi visitar novamente a Pró-reitoria de Extensão, para coletar informações dos estudantes que participaram de ACC desde 2001, a partir da amostra. Na primeira visita à PROEXT, para coleta das informações dos egressos da ACC, colhemos informações de 41 participantes. Enviamos e-mail para os estudantes, telefonamos e o retorno num período de dois meses (agosto e setembro) foi apenas de dois questionários.

Diante da problemática, e já sabendo da dificuldade de localizar egressos, resolvemos não mais colher as informações na 
PROEXT, mesmo porque a organização documental lá existente não contribuiu para a localização das informações dos estudantes que participaram de ACC, e outras vezes que fomos lá para continuar a coleta, duas ou três vezes, não havia nenhum funcionário no local para disponibilizar o material para pesquisa. Assim, resolvemos optar por outras estratégias e também rever a amostra, já que o número inicial de 70 ACC quando multiplicado por 11 (um monitor e dez estudantes) resultaria num número difícil de atingir, mais de 700 egressos, e também por o foco da pesquisa ser o egresso de ACC.

Desta forma, reduzimos a amostra para 70 estudantes, 10\% dos 700 egressos sorteados inicialmente. Além disso, mudamos as estratégias e a amostra. Deixamos cerca de dez questionários em alguns Diretórios Acadêmicos (Matemática, Biologia, Medicina Veterinária, Pedagogia, Administração, Educação Física, Ciências Naturais, Medicina e ICS), totalizando aproximadamente 90 questionários. Deixamos também dez questionários com uma pessoa que trabalha em um órgão da Escola de Administração, dez questionários com uma estudante de Ciências Naturais que ficou de distribuir entre os estudantes que estavam cursando uma ACC em Teatro, 15 questionários com um estudante do MUDA que ficou de entregar aos seus colegas na Faculdade de Filosofia e Ciências Humanas, 20 questionários a uma residente que iria distribuir entre os demais residentes. Só nesse processo distribuímos 145 questionários, além dos 41, a partir dos dados coletados na PROEXT.

Paralelo a esse processo, solicitamos a colaboração de alguns professores via correio eletrônico para nos fornecer os contatos dos egressos de ACC. Os contatos fornecidos totalizaram aproximadamente 32 egressos. Também fomos entregando os questionários a quem conhecíamos.

$\mathrm{Na}$ antepenúltima semana de novembro só havia 27 questionários preenchidos. Diante do prazo da entrega da dissertação, resolvemos criar outras estratégias para localizar os egressos. Assim, no dia 19 de novembro, entramos no orkut e enviamos mensagens para as comunidades existentes de estudantes da UFBA, 21 comunidades. Desse dia até o fim de novembro, 14 egressos responderam o questionário.

Outra estratégia utilizada foi distribuir questionários com os participantes de ACC durante o encontro realizado nos dias 23 
(palestra de abertura do evento no turno noturno) e 24 de novembro (turno vespertino e noturno), Oficina repensar a ACC, pela PROEXT. Conseguimos mais 16 questionários. Assim, tínhamos apenas 58 questionários.

Em seguida, recebemos um questionário via e-mail, provavelmente fruto da colaboração de algum professor com o fornecimento dos contatos dos ex-participantes de ACC. Como ainda não tínhamos o total mínimo esperado, resolvemos distribuir os questionários com os participantes de uma ACC que estava concluindo suas atividades, embora o critério utilizado desde o início da pesquisa foi o de aplicar o questionário apenas com os estudantes que participaram de ACC oferecidas de 2001.1 até 2006.1. Desta forma, obtivemos mais 11 questionários. No mesmo período, uma professora que participa de ACC desde 2001 nos entregou dez questionários, referentes aos estudantes que participam hoje de ACC ou do grupo de pesquisa de responsabilidade da mesma professora.

Enquanto estávamos organizando as informações obtidas dos questionários dos egressos da ACC, recebemos mais dois via correio eletrônico e oito via o D.A. do Curso de Ciências Naturais.

Depois de cinco meses de aplicação dos questionários, conseguimos superar a expectativa mínima dos 70 questionários com um total de 90 questionários dos mais de 218 distribuídos pessoalmente ou por e-mail. Isso significa que o percentual de retorno foi mais de $41 \%$.

No que tange ao tratamento dos dados, utilizamos as técnicas estatísticas de elaboração de tabelas, para melhor analisar os dados quantitativos.

\section{Resultados e discussões}

A Atividade Curricular em Comunidade (ACC) constitui-se em uma das possibilidades da extensão universitária. Sua análise - objeto da dissertação - exigiu que discutíssemos acerca do papel da extensão universitária no currículo de graduação, e mais especificamente o papel da ACC na UFBA e nas IFES.

No tocante ao papel da extensão universitária no currículo de graduação, podemos relembrar que a atual lei de Diretrizes e Bases da Educação Brasileira compreende a extensão como meio de fortalecer a articulação da teoria com a prática nos currículos. 
Para apoiar essa concepção, o Plano Nacional de Educação possui metas referentes à implantação de programas de desenvolvimento da extensão universitária em todas as Instituições Federais de Ensino Superior. Além do reconhecimento legal acerca da importância da extensão no currículo de graduação, o Fórum de Próreitores de Extensão das Universidades Públicas Brasileiras vem elaborando estudos para subsidiar o desenvolvimento das ações extensionistas no âmbito das IFES, publicando, inclusive, as experiências bem-sucedidas na área.

Da discussão acerca dessa temática, podemos concluir que o principal papel da extensão universitária nos currículos de graduação é a possibilidade que o estudante tem de aprender em contato com grupos comunitários, extrapolando as experiências acadêmicas vivenciadas em sala de aula.

Já no que se refere ao papel da ACC na UFBA e nas IFES, discutimos a questão da flexibilização curricular, demanda indispensável dos currículos universitários, e como a ACC pode ser um meio de subsidiar a flexibilização dos currículos de graduação da UFBA.

Por flexibilização, a partir das leituras realizadas, entendemos que é uma possibilidade do estudante possuir maior autonomia para construir seu processo formativo inicial, a graduação, com atenção especial a partir dos seus próprios interesses, combinada com as demandas do mercado de trabalho, e principalmente assegurada no perfil de homem que a sociedade necessita (cidadão ético e humanitário). Além desse entendimento, há alguns princípios que servem como base ao conceber um currículo flexível que são a indissociabilidade entre ensino, pesquisa e extensão, visão do ensino centrada na criatividade, que tem como exigências a construção do conhecimento na relação com a realidade profissional e a interdisciplinaridade.

Concebemos que a ACC contempla todos esses princípios, por isso consideramos que ela tem grande potencial na flexibilização curricular. Destacamos também que a ACC é um componente curricular que pode ser o elemento principal de um novo modelo de organização curricular, em auxílio ao papel que as disciplinas ocupam hoje no currículo de graduação com a vantagem de diminuir a fragmentação do saber, (re)significar o conceito de sala de aula e a proximidade do trabalho com as temáticas referentes às demandas sociais (devido à abertura que a ativida- 
de tem de abordar temas não só do interesse da Universidade como também da comunidade).

É importante frisar também que a Universidade Federal de Minas Gerais está um passo à frente na discussão acerca da flexibilização curricular, pois a instituição possui documentos orientadores sobre a temática, expondo a concepção de currículo, o entendimento de flexibilização, as possíveis formas de tornar um currículo mais flexível, e também alguns desenhos curriculares. Por isso, para discutir a temática, é imprescindível o estudo da experiência da UFMG.

Outro ponto que merece destaque é que a pesquisa iniciou com o propósito de avaliar qual a contribuição da ACC na formação do estudante de graduação da UFBA, articulada com as orientações do Sistema Nacional de Avaliação da Educação Superior (SINAES/MEC). E ao final da pesquisa, além de reunir alguns elementos que podem auxiliar a melhoria do programa, iniciamos, mesmo que timidamente, uma discussão valiosa de uma possível reconceptualização curricular no âmbito da Universidade Federal da Bahia a partir da experiência de seis anos do Programa UFBA em Campo - ACC.

Tal embasamento emergiu devido à pesquisa objetivar, principalmente, verificar qual a contribuição que a ACC possibilita aos seus participantes, no caso os estudantes de graduação da UFBA, no que se refere a sua formação, dentre outras questões.

A primeira questão que orientou o desenvolvimento da pesquisa foi compreender que concepção de extensão e de intervenção social a UFBA possui. Os dados levantados sugerem que, por extensão, a UFBA entende que é o elo entre o ensino e a pesquisa com a sociedade, com caráter interdisciplinar, desenvolvida através de atividades e programas. Já no que se refere à concepção de intervenção social, não há um conceito para a instituição, pois a mesma é compreendida como um princípio presente em todas as práticas extensionistas por ela desenvolvidas. A concepção de extensão universitária da UFBA está de acordo com a definição do Plano Nacional de Extensão Universitária. Embora, para a UFBA, a extensão como assistencialismo esteja superada enquanto conceito, algumas das ACC possuem ainda práticas assistencialistas.

Outro ponto investigado na pesquisa foi verificar se há articulação entre as atividades de ACC e as de ensino e pesquisa e como isso se processa. Os dados levantados apontam que há arti- 
culação, porém consideramos que no caso da ACC essa questão se torna redundante, pois o próprio espírito do programa é a articulação das funções essenciais da Universidade. Assim, o que se pode questionar é em que medida os objetivos da ACC são contemplados. Para um dos entrevistados, por exemplo, em geral as ACC praticam mais ensino que pesquisa. Esse é um dos pontos que a gestão do programa necessita se debruçar, na tentativa de possuir um padrão mínimo de qualidade para o bom funcionamento da atividade, diminuindo discrepâncias, práticas inadequadas, etc.

Uma outra questão de pesquisa foi verificar se existe articulação das temáticas de ACC com os problemas sociais. Como os conteúdos e os temas estão em consonância com as recomendações acerca das áreas temáticas da extensão universitária do Plano Nacional de Extensão, consideramos que há articulação. Um trabalho com outro enfoque pode analisar se cada ACC está de fato trabalhando com as reais demandas da comunidade onde atua. De acordo com os dados levantados, algumas ACC não possuem essa prioridade, pois normalmente levam propostas prontas sem levar muito em consideração o que a comunidade realmente necessita. Assim, consideramos que é importante repensar ou criar uma orientação por parte da gestão do programa para que todas as ACC tomem mais cuidado de apenas esboçar uma proposta, para só depois em contato com a comunidade e juntamente com ela, decidir os rumos do trabalho, convergindo ao máximo os interesses de ambos.

Outro objetivo da pesquisa foi descrever as políticas existentes na UFBA para o desenvolvimento da ACC e verificar se existem incentivos institucionais e ou de outras fontes. Os dados levantados indicam que a própria ACC é considerada como um programa definidor de uma política na UFBA, que é a flexibilização curricular. Por ser considerada uma política, foi necessário discutir a relação entre o programa ACC e a flexibilização curricular, mais especificamente, como a atividade possibilita a flexibilização curricular. Os resultados obtidos sugerem que a ACC auxilia na flexibilização dos currículos de graduação, pois o estudante tem autonomia de escolher qual atividade deseja participar e nela pode desenvolver ações de seu interesse, trabalhando com temas que não foram abordados nas disciplinas do seu curso. Outra característica da ACC que converge com os princípios da flexibilização é

94 R. Faced, Salvador, n.13, p.83-102, jan./jun. 2008 
a interdisciplinaridade, como já foi discutido no decorrer do trabalho, possibilitando que o estudante, por exemplo, participe da análise coletiva de problemáticas a partir de várias áreas do conhecimento.

Além da política da flexibilização curricular, há a política de parceria com financiamento logístico e financeiro com a participação de prefeituras e instituições de apoio à pesquisa e à extensão, e a política de avaliação que já foi discutida, mas ainda não implementada. Consideramos que a realização da oficina Repensar a ACC foi uma das ações iniciais para a prática avaliativa do programa de forma mais sistemática. Além disso, a pesquisa fornece elementos iniciais para o programa ser avaliado como um todo, após seis anos de existência.

Outra questão analisada foi entender como é a participação dos estudantes nas ACC. Os dados levantados mostram que o programa é aberto para todo e qualquer estudante de graduação e pós-graduação. Para os graduandos, a participação formal se efetiva via a matrícula. Ele também pode participar sem se matricular, podendo ser monitor ou colaborador. A comprovação da sua participação só existe para os estudantes matriculados e para os monitores. Desconhecemos comprovação para outros tipos de participação, inclusive para os graduados que muitas vezes continuam participando das atividades. Já para os pós-graduandos, o único meio formal é realizando tirocínio docente. O estudante de pós-graduação também pode ser colaborador. Na ACC, o estudante pode ter experiência de produção compartilhada de conhecimento, compreender o conhecimento como ferramenta de transformação e refletir diversos temas numa perspectiva multidisciplinar que se dá via a composição das equipes de trabalho com estudantes de cursos de graduação diferenciados.

A última questão de pesquisa foi verificar qual a contribuição da ACC na formação do estudante. Os dados levantados indicam que há contribuição na formação do estudante de graduação em alguns aspectos. Dois desses aspectos que colaboram diretamente com a formação profissional do estudante é o desenvolvimento de princípios éticos, indispensáveis hoje no mundo do trabalho, e a capacidade de expressar-se melhor em público, condição necessária ao trabalho em equipe, principalmente quando o indivíduo ocupa cargos de chefia e liderança. 
Outro ângulo que podemos destacar no que se refere aos possíveis ganhos do estudante em participar da ACC é o desenvolvimento de competências e habilidades importantes para a formação continuada em cursos de pós-graduação, que são configuradas na descoberta de novos objetos de investigação em contextos externos ao meio acadêmico (os estudantes podem se interessar por determinadas questões para estudar em mestrados e doutorados a partir da experiência nas ACC), interesse por atividades de pesquisa e maior desenvoltura com a elaboração de texto acadêmico.

Os demais aspectos, que podem ser desenvolvidos nos egressos do programa, auxiliam na formação de um indivíduo mais preparado para atuar como agente transformador, pois eles são estimulados a problematizar como atitude de interação com a realidade, experimentam alternativas metodológicas de trabalho comunitário e potencializam suas atitudes tanto questionadoras como proativas diante dos desafios e limites impostos pela nossa realidade social. Com a possibilidade do desenvolvimento de todos esses aspectos, o egresso se interessa mais pela minimização ou resolução dos problemas sociais, pois ele tem maior aproximação com a vida concreta da sociedade através de um currículo mais flexível.

\section{Conclusões}

Esperamos que os resultados obtidos na pesquisa forneçam uma base de dados que possa ser utilizada pela gestão do programa para iniciar de forma mais sistematizada a implantação de um programa de acompanhamento e avaliação da ACC, com representação da comunidade, dos discentes e dos docentes.

Alguns elementos que podem compor essa base de dados se referem às fragilidades da ACC apontadas no trabalho que vão desde os princípios e diretrizes do programa até o processo de matrícula na atividade. Quanto aos princípios e diretrizes que orientam a elaboração dos projetos ACC, poderá existir o cuidado de praticar uma extensão que não seja assistencialista. No que se refere à distribuição dos recursos por parte da UFBA e de outros órgãos, há a necessidade de ampliar o financiamento que resulta no aumento do número de ACC e no oferecimento de melhores condições de trabalho para as equipes que compõem as ativida- 
des. Já em relação a metodologia de ensino-aprendizagem, os dados levantados apontam para a necessidade de repensar o papel do professor, coordenador da ACC, como também do monitor. Esses são alguns dos elementos que podem compor esse banco de dados inicial.

Assim, acreditamos que se esses pontos destacados forem reformulados, em total articulação com essa nova fase que a UFBA está vivenciando da gestação da Universidade Nova, a ACC se tornará um dos fortes aliados para o aumento da qualidade na formação, via a reconceptualização do currículo, pois a proposta da UFBA visa a sua reestruturação da arquitetura acadêmica, tendo como um de seus objetivos a flexibilização curricular através do aumento dos componentes curriculares que se traduzirão em um elenco maior de possibilidades a disposição do graduando, para ele escolher que caminho acadêmico trilhar. Consideramos, desta forma, que a ACC pode auxiliar na consecução desse objetivo e também pode satisfatoriamente ser um definidor curricular, auxiliando o papel que a disciplina hoje preenche no currículo, superando a fragmentação do conhecimento, a falta de interdisciplinaridade, possibilitando a produção compartilhada do conhecimento.

Além de subsidiar o objetivo da flexibilização, a ACC já realiza a integração entre conteúdos disciplinares (outra característica desejada pela proposta da Universidade Nova) e contribui para as escolhas profissionais, evitando decisões precoces, uma vez que convivendo com as comunidades, em contato constante com os problemas sociais, o estudante poderá se perceber mais sensível a estudar determinado curso, a trabalhar em determinada área. Nessa perspectiva, a ACC pode funcionar como um estágio profissional, onde o estudante terá a possibilidade de vivenciar e amadurecer a escolha por uma profissão.

À guisa de conclusão, gostaríamos de finalizar o artigo expondo que a ACC é uma das experiências acadêmicas da UFBA que transita de forma articulada entre as funções essenciais da Universidade (o ensino, a pesquisa e a extensão) de forma prazerosa, instigante e estimulante para os que dela participam, possibilitando, ainda que de forma indireta, a vivência do que é fazer Universidade para aqueles que dela não participam formalmente, a Comunidade. 


\title{
The UFBA em Campo Extension Program - ACC: its contributions to students training
}

\begin{abstract}
This paper intended to evaluate UFBA em Campo Extension Program - ACC, from undergraduate alumni point of view. Six objectives were established: the first one was to understand the concept of extension and social intervention adopted at UFBA; the second one was to verify the existence of connections between ACC extension, research and teaching, and how it occurs; the third one was the existence of connections between ACC extension and social problems; the fourth one was to describe UFBA policies to develop ACC and the existence of institutional, and other sources, of encouragement of the program; the fifth one was how to understand students participation and the sixth and last one was the exam of its contributions to students training. The study, conducted on basis of bibliographic and documental research and survey, revealed that UFBA adopts, through the ACC practice, the same concept established in National Plan of University Extension, considering the concern for social problems as an university function. The research has indicated that UFBA applies institutional policies for ACC development (policies of partnership, assessment and curriculum flexibility) and also that ACC program plays an important role in students academic path, contributing to develop ethical, professional, humanitarian attitudes, as well citizenship.

KEY-WORDS: Institutional evaluation. University extension. Curriculum flexibility.
\end{abstract}

\section{Referências}

BOTOMÉ, Silvio Paulo. Pesquisa alienada e ensino alienante : o equívoco da extensão universitária. Petrópolis, RJ: Vozes; São Carlos, SP: EDUFSCar, 1996.

BRASIL. Lei $n^{\circ} 5.540$, de 28 de novembro de 1968. Fixa normas de organização e funcionamento do ensino superior e sua articulação com a escola média, e dá outras providências. Disponível em: < http:/ /mp.pr.gov.br/institucional/capoio/cidadania/fundacoes/legisla/.../ 05540 68.ht >. Acesso em: 25 nov.2003.

BRASIL. Lei $\mathrm{n}^{\circ}$ 9.394, de 20 de dezembro de 1996. Estabelece as diretrizes e bases da educação nacional. Disponível em: <http:// portal.mec.gov.br/seed/arquivos/pdf/tvescola/leis/lein9394.pdf > . Acesso em: 20 nov. 2007.

BRASIL. Lei $\mathrm{n}^{\circ} 10.173$ de 9 de janeiro de 2001. Aprova o Plano Nacional de Educação e dá outras providências. Diário Oficial da União, Brasília, DF, 10 jan. 2001. Disponível em: <http://www010.dataprev.gov.br/sislex/ paginas/42/2001/10173.htm > 20 nov. 2007

BRASIL. Ministério da Educação. Anteprojeto de lei. Estabelece normas gerais para a educação superior, regula o Sistema Federal da Educação Superior e dá outras providências. < http://www.adurrj.org.br/4poli/gruposadur/gtpe/reforma_univ_proj_lei_maio_2006. pdf > Acesso em: 5 jan. 2005. Versão preliminar: 06 dez. de 2004. 
Sistema Nacional de Avaliação da Educação Superior - SINAES: bases para uma nova proposta de avaliação da Educação Superior. [Brasília], 2003. Disponível em: < http://www.unifesp.br/reitoria/ orgaos/comissoes/avaliacao/sinaes.pdf. >. Acesso em: 27 dez. 2007.

BRASIL. Parecer CNE/CES n. 776, de 03 de dezembro de 1997. Orientação para as diretrizes curriculares dos cursos de graduação. Disponível em: <http://portal.mec.gov.br/setec/arquivos/pdf/ PCNE776_97.pdf >. Acesso em: 25 nov.2003.

BRASIL. Parecer CNE/CES n. 583, de 04 de abril de 2001. Orientação para as diretrizes curriculares dos cursos de graduação. Disponível em: <http://portal.mec.gov.br/cne/arquivos/pdf/2001/pces583_01. pdf>. Acesso em: 25 nov.2003.

CONFERÊNCIA MUNDIAL SOBRE O ENSINO SUPERIOR, 1998, Paris. Tendências da Educação Superior para o Século XXI. UNESCO, Conselho de reitores das universidades públicas.

DELORS, Jacques (Org.). Educação: um tesouro a descobrir. 2. ed. São Paulo: Cortez, 1999. p.139-151. Relatório para a UNESCO da Comissão Internacional sobre Educação para o século XXI.

DEMO, Pedro. Pesquisa: princípio científico e educativo. São Paulo: Cortez, 2001.

2001 .

Pesquisa e informação qualitativa. Campinas, SP: Papirus,

Saber pensar. São Paulo: Cortez, 2001.

FARIA, Dóris Santos de (Org.). Construção conceitual da extensão universitária na América Latina. Brasília: Universidade de Brasília, 2001.

FORUM NACIONAL DE PRÓ-REITORES DE EXTENSÃO DAS UNIVERSIDADES PÚBLICAS BRASILEIRAS, 8., 1994:Vitoria, ES. Anais ... Vitoria: UFES, Ed. Universitária, 1994.

FÓRUM NACIONAL DE PRÓ-REITORES DE EXTENSÃO DAS UNIVERSIDADES PÚBLICAS BRASILEIRAS. Avaliação nacional da extensão universitária. Ilhéus, BA: Editus, 2001. 98 p. (Extensão Universitária; v.3).

FÓRUM NACIONAL DE PRÓ-REITORES DE GRADUAÇÃO DAS UNIVERSIDADES BRASILEIRAS, 12. Concepções e implementação da flexibilização curricular. Disponível em: < http://www.prograd.ufu.br/ forgrad2004 >. Acesso em: 28 out. 2006.

FÓRUM NACIONAL DE PRÓ-REITORES DE EXTENSÃO DAS UNIVERSIDADES PÚBLICAS BRASILEIRAS. Extensão universitária e a flexibilização curricular. Brasília: MEC/SESu; Porto Alegre: UFRGS; 2006. (Extensão Universitária; v.4).

FÓRUM NACIONAL DE PRÓ-REITORES DE EXTENSÃO DAS UNIVERSIDADES PÚBLICAS BRASILEIRAS. Indissociabilidade ensino-pesquisa-extensão e a flexibilização curricular: uma visão da extensão. Brasília: 
MEC/SESu; Porto Alegre: UFRGS, 2006. (Extensão Universitária v. 4). < Disponível em:<http://www2.unifal-mg.edu.br/extensao/files/ file/colecao_extensao_univeristaria/colecao_extensao_universitaria_ 4_indissociabilidade.pdf >. Acesso em: 2 jul. 2006].

FÓRUM NACIONAL DE PRÓ-REITORES DE EXTENSÃO DAS UNIVERSIDADES PÚBLICAS BRASILEIRAS. Plano Nacional de Extensão Universitária. [S.1.: s.n., 2001?] Disponível em:< http://proex.epm.br/ projetossociais/renex/plano_nacional.htm >. Acesso em: 27 jan. 2007.

FÓRUM NACIONAL DE PRÓ-REITORES DE GRADUAÇÃO DAS UNIVERSIDADES BRASILEIRAS, 12., Ilhéus, BA., 1999. Plano Nacional de Graduação: um projeto em construção. Ilhéus, BA: Editus, 2001. 98 p. (Extensão Universitária; v.3) Disponível em: $<\underline{\text { http:// }}$ www.unicamp.br/prg/forgrad > Acesso em: 1 set. 2004.

FRANTZ, Walter; SILVA, Enio Waldir da. As funções sociais da universidade: o papel da extensão e a questão das comunitárias. Ijuí: Ed. Unijuí, 2002.

FREIRE, Paulo. Extensão ou comunicação? 4. ed. Rio de Janeiro: Paz e Terra, 1979 .

INEP. SINAES: Sistema Nacional de Avaliação da Educação Superior: orientações gerais para o roteiro da auto-avaliação das instituições. Brasília, 2004. Disponível em: <http://www.inep.gov.br/download/ superior/sinaes/orientacoes_sinaes.pdf>. Acesso em: 27 jan. 2007.

JEZINE, Edineide Mesquita. Abordagens teóricas e concepções de extensão universitária. In: ENCONTRO DE PESQUISA EDUCACIONAL DO NORTE E NORDESTE, 16., 2003, Aracajú. Programação e resumos ... Aracajú: [s.n.], 2003. 1 CD

Universidade e saber popular: o sonho possível. João Pessoa: Autor Associado; CCHLA-UFPB, 2002.

LIMA, Paulo Costa. Novos rumos na interface universidade-sociedade. Folha de São Paulo, São Paulo, 15 nov. 2000. p. 3. Disponível em: < http://www.acc.ufba.br/repercu/textos/novrum.html >. Acesso em: 12 nov. 2003.

MAGNARI, Ivetti. Ensino, pesquisa, extensão e a nova tipologia do ensino superior brasileiro. In: REUNIÃO ANUAL DA ANPED, 25., 2002, Caxambu, MG. Caxambu, MG: Anped, 2002. Disponível em: < http:/ /www.anped.org.br/25/ivettimagnarit11.rtf > Acesso em: 22 out. 2005.

MAZZILLI, Sueli. Ensino, pesquisa e extensão: uma associação contraditória. 1996. 201 f. Tese (Doutorado em Educação) - Centro de Educação e Ciências Humanas, da Universidade Federal de São Carlos, São Carlos, São Paulo, 1996.

MELO NETO, João Francisco de. Extensão universitária: diálogos populares. João Pessoa: Ed. Universitária, 2002. $\overline{\text { ria, } 2004}$

Extensão universitária é trabalho. João Pessoa: Ed. Universitá-

100 R. Faced, Salvador, n.13, p.83-102, jan./jun. 2008 
Extensão universitária, autogestão e educação popular. João Pessoa: Ed. Universitária, 2004.

MESQUITA, J.E. Multiversidade e extensão universitária. In: ENCONTRO DE PESQUISA EDUCACIONAL DO NORTE E NORDESTE, 15., 2001, São Luis. Programação e resumos... São Luis:[s.n.], 2001. 1 $\mathrm{CD}$

MOREIRA, Antonio Flávio Barbosa. Currículo, utopia e pósmodernidade. In: MOREIRA, Antonio Flávio Barbosa (Org.). Currículo: questões atuais. Campinas, Sp: Papirus, 1997.

MOROZ, Melania; GIANFALDONI, Mônica Helena Tieppo Alves. O processo de pesquisa: iniciação. Brasília: Plano, 2002.

NOGUEIRA, Maria das Dores Pimentel (Org.). Extensão universitária: diretrizes conceituais e políticas. Belo Horizonte: PROEX/UFMG, 2000.

SANTOS, Boaventura de Sousa. Da ideia de universidade à universidade de ideias. In: Pela mão de Alice: o social e o político na pós-modernidade. 9.ed. São Paulo: Cortez, 2003.

SERPA, Felippe. Rascunho digital: diálogos com Felippe Serpa. Salvador: Edufba, 2004.

SILVA, Maria das Graças. Universidade e sociedade: cenário da extensão universitária? In: REUNIÃO ANUAL DA ANPED, 23., 2000, Caxambu, MG. Caxambu, MG: Anped, 2000. Disponível em: < http:/ /www.anped;org.br/23/textos/1101T.PDF >. Acesso em 28 dez. 2007.

SILVA, S. C. F. da. Extensão universitária e trabalho social. In: ENCONTRO DE PESQUISA EDUCACIONAL DO NORTE E NORDESTE, 15., 2001, São Luis. Programação e resumos... São Luis:[s.n.], 2001. 1 CD

SOUSA, Ana Luiza Lima. A história da extensão universitária. Campinas, SP: Alínea, 2000.

TAVARES, Maria das Graças Medeiros. Extensão universitária: novo paradigma de universidade? Maceió: EDUFAL, 1997.

TEIXEIRA, Anísio. A Universidade de ontem e de hoje. Revista Brasileira de Estudos Pedagógicos, Rio de Janeiro, v. 42, n. 95, p.27-4, jul./ set. 1964. Disponível em: < < http://www.bvanisioteixeira.ufba.br/ artigos/ontem.html> Acesso em: 30 nov. 2004].

Funções da universidade. Boletim Informativo CAPES, Rio de Janeiro, n. 135, p. 1-2, fev. 1964. Disponível em: < http:// www.bvanisioteixeira.ufba.br/artigos/funcoes.html> Acesso em: 30 nov. 2004.

TEIXEIRA, Anísio. Uma perspectiva da educação superior no Brasil. Revista Brasileira de Estudos Pedagógicos, Brasília, v. 50, n. 111, p. 21-82, jul./set. 1968. Disponível em: < http://www.bvanisioteixeira.ufba.br/ artigos/perspectiva.html> Acesso em: 30 nov. 2004. 
TOBIAS, José Antônio. Universidade: humanismo ou técnica? São Paulo: Herder, 1969.

UNIVERSIDADE FEDERAL DA BAHIA. Conselho de Coordenação. Câmara de Extensão. Resolução $n^{0}$ 002/96. Dispõe sobre as atividades de extensão, revogando as normas vigentes, e dá outras providências. 